\title{
Matemática Financeira e Robótica Educacional: Robôparque de aprendizagem divertida
}

\author{
Brenda P. Machado ${ }^{1}$, Beatriz S. Ribeiro², Gessiene S. Santos ${ }^{2}$, Crhistiane F. Souza ${ }^{2}$, \\ Fernando C. Barbosa ${ }^{2}$ \\ ${ }^{1}$ Unidade Acadêmica Especial de Matemática e Tecnologia - Universidade Federal de \\ Goiás - Regional Catalão (UFG) \\ ${ }^{2}$ Unidade Acadêmica Especial de Matemática e Tecnologia - Universidade Federal de \\ Goiás - Regional Catalão (UFG) \\ (brendapedroso1,gessienesoares09)@hotmail.com, (beatriz.siqueira0123, crhisf.souza, \\ fermat.ufu)@gmail.com
}

\begin{abstract}
This article aims to present as experiences lived and unleashed by the Institutional Program of Scholarship Initiation to Teaching (PIBID), Federal University of Goiás - Regional Catalão, subproject of Mathematics. We used a qualitative research on Educational Robotics, focusing on a case study, aiming at a contribution to students' mathematical learning. Here we present one of the activities developed by subprojects, available for a construction of an amusement park, using a solution of an amusement park, using a basic financial mathematics tool from a park structure to a set of tools. Its functioning.
\end{abstract}

Resumo. Este artigo visa apresentar as experiências vividas e desencadeadas pelo Programa Institucional de Bolsas de Iniciação à Docência (PIBID), da Universidade Federal de Goiás - Regional Catalão, subprojeto de Matemática. Utilizamos a pesquisa qualitativa sobre Robótica Educacional, com enfoque em estudo de caso, visando a contribuição desta para a aprendizagem matemática dos alunos. Aqui apresentamos uma das atividades desenvolvidas pelo subprojeto, cuja proposta foi a construção de um parque de diversões utilizando robôs idealizados pelos alunos do $6^{\circ}$ ano do Ensino Fundamental de uma escola parceira do PIBID, onde contextualizamos a matemática financeira básica desde a estrutura do parque até o seu funcionamento.

\section{Considerações Iniciais}

O desenvolvimento tecnológico tem possibilitado ao ser humano realizar tarefas em diversos âmbitos de forma rápida, permitindo assim economia de tempo e sua maior realização. Tais tarefas têm sido realizadas através da informática, que segundo Barbosa (2013, p. 29) pode ser considerada um instrumento relevante para o desenvolvimento da Robótica, um dos maiores avanços tecnológicos que permite, em diferentes momentos, substituir o homem em situações de risco. A Robótica tem se mostrado eficiente e tem- 
se percebido, com o desenvolvimento científico, suas várias colocações como ferramenta. No ensino não foi diferente, denominada como Robótica Educacional, sua utilização como instrumento de ensino tem surpreendido educadores de diversas áreas, onde o aluno participa de todo processo de construção do robô, desde a montagem até sua programação e isso possibilita ao professor contextualizar conteúdos trazendo assim maior interesse dos alunos em aprender, como dito por Barbosa (2013)

\begin{abstract}
Nesse sentido, a robótica transcende um conjunto de peças e montagem de robôs, alcançando um contexto de produção intelectual e desenvolvimento cognitivo capaz de preparar um indivíduo a pensar coletivamente e fazer do seu consumo (conhecimento e informação) um processo de produção e autoria. (BARBOSA, 2013, p. 3)
\end{abstract}

O destaque desta nuance tem possibilitado sua inclusão em projetos que visam a aprendizagem no ensino, pois permite uma interação geral, sendo de aluno para aluno e de professor para aluno, como Moraes (2010, p. 19) afirmou que com a utilização de tecnologias no cotidiano dos alunos seu envolvimento é maior, devido a familiarização. Assim a Robótica Educacional se propõe a buscar o interesse dos alunos por aprender matemática, pois nos permite trabalhar de forma lúdica os conteúdos com os alunos tornando assim as aulas mais proveitosas e interativas. Assim como disseram Miranda, Sampaio e Borges (2010)

\begin{abstract}
A robótica educacional é uma atividade desafiadora e lúdica, que utiliza o esforço do educando na criação de soluções de hardware e software visando a resolução de uma situação-problema proposto. Alguns projetos pedagógicos de robótica em sala de aula fazem uso, por exemplo, da teoria construtivista de Jean Piaget para auxiliar o processo de ensino permitindo ao aluno, no processo de construção do conhecimento, a oportunidade de participar de uma aprendizagem mais efetiva e desenvolver uma percepção mais acurada dos fenômenos científicos. (MIRANDA, SAMPAIO, BORGES, 2010, p. 47)
\end{abstract}

Já Zilli (2004, p.39) se posiciona diante do olhar do professor, entendendo que a Robótica Educacional "é uma ferramenta que permite ao professor demonstrar na prática muitos dos conceitos teóricos, às vezes de difícil compreensão, motivando o aluno, que a todo momento é desafiado a observar, abstrair e inventar". Nesse sentido, precisamos construir ações que não somente demonstrem na prática conceitos, mas que fazem da prática uma investigação de desenvolvimento e aprendizagem de conhecimentos científicos, em nosso caso, conhecimentos matemáticos.

Sendo assim, nós enquanto professores de matemática, devemos procurar a melhor forma de ensinar nossos alunos os conteúdos referentes ao currículo. E é perceptível como a Robótica Educacional

\footnotetext{
há muito vem se incorporando às práticas dos professores e o caso apresentado neste texto é apenas uma das muitas experiências que se desenvolvem Brasil afora. É bem verdade que não se atingiu, ainda, a universalização de tal prática, no entanto, não pode mais ser considerada uma novidade nas escolas de Educação Infantil, Fundamental e Médio. Assim, nas escolas onde se vivencia tal experiência, pode-se afirmar que a robótica faz parte do currículo. (ABREU, BASTOS, 2015, p. 5)
}

Mesmo sendo pouco o acesso a todas as escolas brasileiras, a Robótica Educacional tem se mostrado eficaz nesta articulação, pois seguindo a proposta de Modelagem Matemática, se permite modelar à diversos conteúdos das diversas áreas, podendo seus variados protótipos serem moldados aos níveis de ensino, onde na 
matemática caminha aos extremos, indo desde frações até a análise de funções e suas diferentes modalidades, levando em conta que também estimula o raciocínio lógico e coordenação motora

Por outro lado, pensando na formação do professor, destacamos o Programa Institucional de Bolsas de Iniciação à Docência (PIBID), que tem como um de seus objetivos elevar a qualidade da formação inicial de professores, nos cursos de Licenciatura, para a Educação Básica. O PIBID da Universidade Federal de Goiás Regional Catalão, subprojeto na área de matemática permite aos bolsistas seu primeiro contato com o âmbito escolar, levando-o a compreender o cotidiano do espaço escolar da rede pública, tanto municipal quanto estadual, entender seus principais problemas e desafios e ao mesmo tempo buscar as soluções e propostas para elevar a qualidade do fazer docente.

O subprojeto supracitado busca ainda superar a dicotomia entre a teoria e a prática a partir da troca de experiências e saberes entre a Universidade e a Escola Básica. Empenha em contribuir para a melhoria da qualidade da Educação Básica através de atividades diferenciadas de caráter investigativo e estimulante, que possam provocar nos alunos da escola a curiosidade e a vontade de aprender Matemática. Assim, os bolsistas são estimulados a conhecer e se posicionar mediante diferentes metodologias de ensino e desenvolver a que encontra mais facilidade e mobilidade para trabalhar e que permita assim bons resultados na aprendizagem dos alunos.

Diante das potencialidades da Robótica Educacional, surgiu dentro deste subprojeto a oportunidade de conhecer essa proposta metodológica, o que levou o interesse de alguns bolsistas a trabalharem nesta área, vendo possibilidades e bons resultados que poderiam ser obtidos a partir desta. Com isso, iniciamos o trabalho dentro de uma das escolas parceiras do PIBID, a "Escola CAIC São Francisco de Assis". Ela é uma escola do município de Catalão-GO que dispõe do material necessário para aplicação da Robótica Educacional, e que ofereceu, juntamente com a Professora Supervisora do subprojeto, condições necessárias para a execução desta ação junto a alunos do $6^{\circ}$ (sexto) ano do Ensino Fundamental. Foi construído um parque de diversões, o Robôparque, utilizando protótipos robóticos a partir da idealização dos alunos e sob nossa orientação.

\section{Abordagem temática}

Toda nova estrutura de abordagem metodológica, visa melhor aproveitamento do conteúdo proposto em sala de aula, quando a Robótica foi incorporada no meio educacional não foi diferente. Uma vertente de introdução da Robótica Educacional é de forma lúdica, misturando a teoria com a prática, utilizando a construção de robôs para o ensino-aprendizagem. Um dos motivos do uso da tecnologia na educação é a motivação que ela traz para os alunos, já que as tecnologias estão inseridas em seu cotidiano, e para eles o uso da abordagem tradicional de ensino (quadro, giz, livro) já seja desmotivante, assim novas ferramentas educacionais permitem uma motivação por parte do aluno e estimula a sua aprendizagem, pois

O uso de ferramentas educacionais computadorizadas contribui como fator motivacional para estimular a aprendizagem, e permite que uma criança desenvolva suas habilidades em matemática a partir do aspecto lúdico- 
VI Congresso Brasileiro de Informática na Educação (CBIE 2017)

Anais do XXIII Workshop de Informática na Escola (WIE 2017)

didático intrínseco nestas ferramentas, onde assim, é possível aprender matemática brincando. (LOPES et al., 2016, p. 42)

Com isso vemos que a utilização de situações cotidianas dos alunos permitem uma melhor contextualização do conteúdo e um melhor entendimento do que se quer tratar, e a abordagem temática permite ao aluno construir seu próprio conhecimento que é primordial no ensino, como dito por Freire (2003, p. 47) "Ensinar não é transmitir conhecimento, mas criar as possibilidades para sua própria produção ou a sua construção".

Não somente Paulo Freire, mas também Seymour Papert (2008, p. 38) enfatiza a autoconstrução do conhecimento, deixando claro a libertação de uma própria estrutura por parte do aluno "o que mais gosto é a oportunidade oferecida aos estudantes de libertarem-se de sua própria estrutura para engajar-se em atividades mais auto direcionadas."

\section{Metodologia}

Este trabalho trata das experiências vividas e desencadeadas pelo Programa Institucional de Bolsas de Iniciação à Docência (PIBID), da Universidade Federal de Goiás Regional Catalão (UFG), subprojeto da área de Matemática. O subprojeto busca trabalhar a aprendizagem matemática de diversas formas, sendo elas: Robótica Educacional, Modelagem Matemática, Etnomatemática, Jogos Lúdicos etc. Dentro destas nuances, uma que tem se destacado e mostrado resultados dentro do subprojeto é a Robótica Educacional, que expressa de forma imediata o interesse do aluno e a motivação, permitindo também envolvimento entre os alunos e o desenvolvimento do raciocínio lógico que contribui para a construção do conhecimento do aluno.

O trabalho foi elaborado a partir de um plano de trabalho de um grupo de bolsistas, cujo principal objetivo é potencializar a formação docente do bolsista e proporcionar uma aprendizagem matemática dos alunos através da Robótica Educacional. Este é orientado pela ideia de pesquisa qualitativa com características de estudo de caso, que permite ao pesquisador contato com o objeto de estudo e seu ambiente, assim presenciando acontecimentos importantes para a pesquisa, o que Rey $(2005$, p. 105$)$ entende como "um processo aberto submetido a infinitos e imprevisíveis desdobramentos, cujo centro organizador é o modelo que o pesquisador desenvolve e em relação ao qual as diferentes informações empíricas adquirem significados".

O projeto está em desenvolvimento até o fim deste ano letivo com a participação do $6^{\circ}$ (sexto) ano do Ensino Fundamental da Escola Caic São Francisco de Assis, na cidade de Catalão-GO, parceira do subprojeto supracitado. Um diferencial desta escola é que ela, sendo uma escola municipal, recebeu da prefeitura os Kits LEGO ${ }^{\circledR}$ Mindstorms Education NXT 2.0 em 2012, entretanto, por diversos fatores, poucas vezes eles foram utilizados até então.

Atualmente a escola possui aproximadamente 20 kits LEGO ${ }^{\circledR}$ Mindstorms NXT, que foram divididos para serem trabalhados em dois turnos, matutino e vespertino, coordenados por duas equipes de bolsistas do PIBID. A professora supervisora do subprojeto que trabalha na instituição, realizou a seleção dos alunos através de um sorteio, pois o número de vagas era limitado em virtude de ser ofertado apenas em dois dias e pelo número de material e recurso humano para trabalhar. Assim, foram 
selecionados vinte e quatro alunos das quatro turmas de $6^{\circ}$ anos, ficando assim, dois grupos com 12 alunos que se deslocam à escola nos seus respectivos contra turnos.

As atividades do projeto ocorrem no laboratório de informática da escola, onde tal possui uma boa acomodação e suporte necessário para o desenvolvimento do projeto, e também a necessária instalação dos programas para a montagem e programação dos robôs. Em um destes momentos acontece o trabalho do qual se originou a proposta que aqui estamos descrevendo, e que já tem mostrado resultados na aprendizagem matemática dos alunos e na formação docente dos bolsistas. Essa equipe é formada por uma professora supervisora da escola, quatro bolsistas e dois orientadores.

A utilização desta abordagem dentro do subprojeto partiu do interesse de um bolsista por Robótica Educacional. Com o trabalho bem executado deste bolsista viu-se diversas possibilidades para ampliar os trabalhos nesta área, e assim abriu vaga para escolas parceiras que haviam o material necessário composto por softwares e hardwares $\left(\right.$ LEGO $^{\circledR}$ Mindstorms NXT 2.0), e isto permitiu a entrada de uma nova escola parceira no subprojeto. Com todo encaminhamento pronto se iniciou no segundo semestre do ano de 2016 o trabalho com Robótica Educacional nesta escola e assim tem continuado atualmente. Vale ressaltar que naquele ano havíamos proposto apenas uma turma de robótica e devido à grande procura e reconhecimento do nosso trabalho diante da comunidade escolar, e principalmente, pela nossa familiaridade com a metodologia, o projeto foi expandido para duas turmas neste ano.

O kit utilizado no subprojeto denominado LEGO ${ }^{\circledR}$ Mindstorms NXT foi lançado pela LEGO $^{\circledR}$ em 2006, este dispõe de peças que compõe todo corpo do robô, onde o Brick NXT, que funciona como cérebro do robô e guarda todas as informações da programação e as executam conforme definido, se conecta com todo o corpo do robô, desde as partes que constituem o seu corpo até os sensores e motores. Para a etapa de programação do robô a LEGO ${ }^{\circledR}$ dispõe do software LEGO ${ }^{\circledR}$ Mindstorms NXT, onde em seu corpo possui diversas ações e atividades divididas em blocos que permite uma programação mais eficaz e acessível. Toda a programação desenvolvida pode ser transmitida para o robô via USB ou bluetooth.

Nossa proposta consiste na construção do parque de diversões, o Robôparque, com o material descrito, que foi trabalhada numa sequência didática com duração de 3 (três) aulas de 2 (duas) horas e meia cada. A sugestão era que cada grupo, constituído por 3 (três) alunos, construíssem um robô que fosse um protótipo de um brinquedo presente em um parque de diversões, onde os grupos não pudessem construir protótipos iguais entre si, para que a constituição do parque fosse concretizada. Porém, o maior desafio era que a construção do robô deveria ser feita sem nenhum auxílio de montagem que disponibilizasse o passo a passo (PDFs ou LEGO Designer), com isso os alunos poderiam utilizar apenas de imagens diversas e esboços construídos por eles. É importante destacar que até o momento desta proposta os alunos já haviam participado de outras sequências didáticas que utilizavam destes recursos para auxiliá-los na construção dos robôs.

Com a proposta dada, os grupos escolheram seus brinquedos para construção do protótipo e na aula seguinte trouxeram esboços que pudessem auxiliá-los na construção (Figura 1). Na primeira etapa os alunos deveriam escolher por si mesmos as peças necessárias, para que houvesse melhor desempenho e funcionamento do robô, além de torná-lo mais parecido com o modelo original. 
VI Congresso Brasileiro de Informática na Educação (CBIE 2017)

Anais do XXIII Workshop de Informática na Escola (WIE 2017)

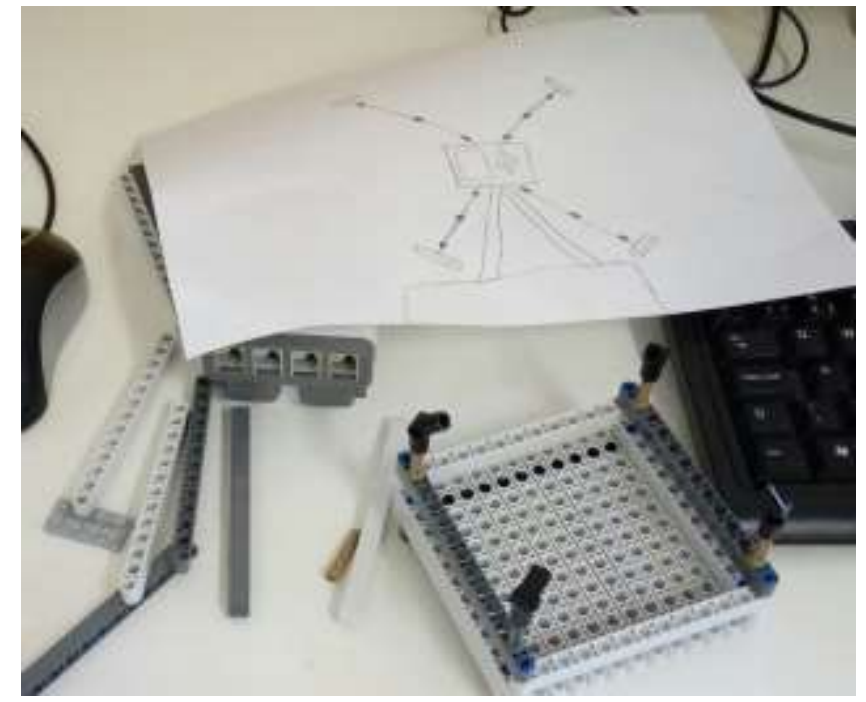

Figura 1. Esboço.

Fonte: Próprio autor.

$\mathrm{Na}$ segunda etapa, os alunos aprimoraram seus protótipos para que ficassem mais parecidos com o brinquedo escolhido. Ao terminarem a montagem, começaram a programá-lo, colocando-o para funcionar conforme suas expectativas e funcionalidades específicas. Já na terceira aula, os alunos construíram a maquete do parque para alocar seus robôs (Figura 2), dando vida e funcionamento ao parque de diversões, ou melhor, ao nosso Robôparque. Nesta aula, foi introduzido o conteúdo de matemática financeira, contextualizando os custos de investimento para a elaboração de um projeto como um parque de diversões, as despesas que se tem para sua devida permanência como negócio que gera lucros, os lucros que são obtidos a partir da venda do produto e que todo estes conceitos são necessários para uma boa administração financeira.

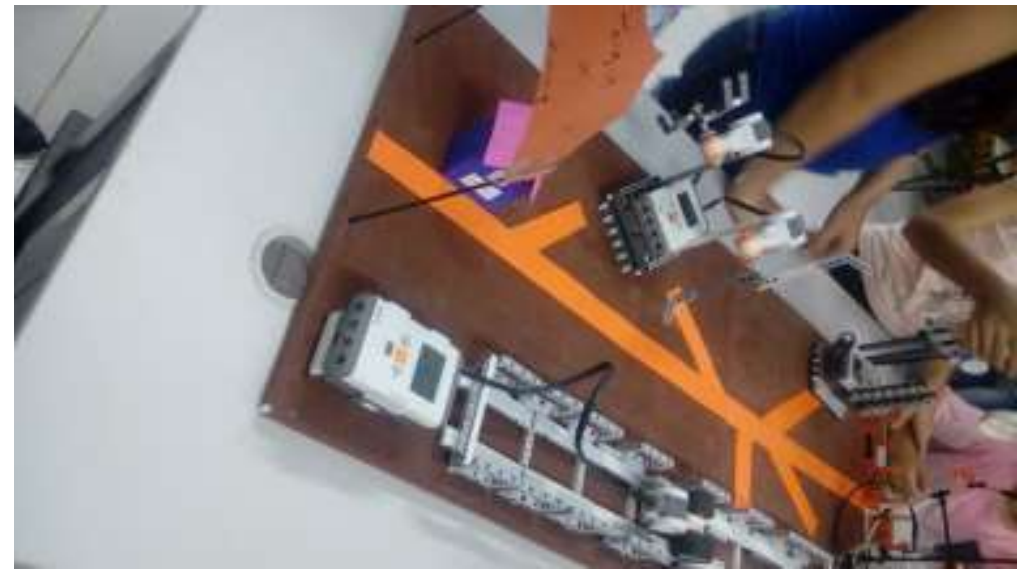

Figura 2. Maquete do Robôparque

Fonte: Próprio autor. 
Para percepção das aprendizagens obtidas pelos alunos diante da proposta, aplicou-se questionários individuais, visando qualitativamente, suas expectativas, dificuldades, facilidades, como o projeto os auxilia nos conteúdos matemáticos e a importância que o projeto tem para eles enquanto alunos.

\section{Resultados}

A proposta da Robótica Educacional dentro da escola parceira consistia em estimular os alunos a construírem robôs, programá-los e participarem dos desafios e atividades propostos, visando em todo esse processo com o robô trabalhar conteúdos matemáticos. Esta proposta gerou na escola curiosidade, onde todos os alunos que conheciam ou tinham informação do que era feito, demonstrava interesse em participar do projeto. Frequentemente, a escola posta em suas redes sociais, fotos e vídeos das ações desenvolvidas durante o projeto de robótica, causando euforia e grande interesse, tanto por parte dos alunos da escola quanto por parte dos pais destes.

O primeiro protótipo trabalhado foi o Jipe Lunar que possibilitou explorar o básico da Robótica, tanto na parte de construção como na parte de programação, para que assim os alunos pudessem familiarizar com todo processo. Este deixou os alunos motivados para os próximos robôs. Como o projeto ocorre no contra turno dos alunos, percebemos que o índice de faltas era quase nulo, e que todas as atividades propostas, seja em classe ou para casa, eram realizadas, o que mostra o comprometimento dos alunos pelo projeto.

Os protótipos anteriores ao Robôparque foram importantes para o desenvolvimento do pensamento lógico e da coordenação motora, o que levou a equipe a pensar em uma proposta mais elaborada, que trabalhasse a criatividade e o espírito inovador, onde os alunos se sentissem mais motivados à aprender, e que os desafiassem, pois contextualizaria um interesse geral da turma. Já dizia o percursor da robótica educacional, "as crianças, tal como todas as outras pessoas, não preferem a facilidade querem o desafio e o interesse, o que implica dificuldade" (PAPERT, 1996, p. 83-84). Por outro lado,

A motivação tornou-se um problema de ponta em educação, pela
simples constatação de que, em paridade de outras condições, sua
ausência representa queda de investimento pessoal de qualidade nas
tarefas de aprendizagem. Alunos desmotivados estudam muito pouco
ou nada e, consequentemente, aprendem muito pouco. (BZUNECK
apud JESUS, 2011, p. 20-21)

Quando a proposta foi apresentada, ela se mostrou como um desafio aos seus conhecimentos até então construídos. Na primeira aula, ao se depararem com diversas peças que eles deveriam escolher sozinhos, ficaram um pouco perdidos, mas logo sentiram-se confortáveis com a liberdade de escolha das peças para o protótipo escolhido, mostrando assim livres no processo criativo de um novo projeto. Percebemos como o desafio proposto foi um elemento crucial para manter a motivação dos alunos em construir algo que ainda não haviam experienciado. Fomos percebendo que os alunos utilizaram até mesmo peças que não haviam tido contato nos protótipos anteriores. Mesmo sendo desafiados, dois grupos concluíram seus protótipos com 
rapidez, e com isso puderam ajudar os outros grupos que estavam com mais dificuldade, o que levou a um trabalho em equipe, onde todos os 12 (doze) alunos estavam envolvidos.

Manchope afirma que

investir em capital humano é imprescindível para a produtividade. Para tanto, o indivíduo deve destacar-se pela inovação, criatividade e autonomia. O professor possui um papel determinante, uma vez que a ele cabe "despertar a criatividade, desenvolver a autonomia, estimular o rigor intelectual e criar as condições necessárias para o sucesso da educação formal e da educação permanente". (MANCHOPE apud MAIESKI, OLIVEIRA, BZUNECK, 2013, p. 53)

O momento da programação mostrou a autonomia dos alunos, estes tiveram boa performance, pois já tinham ideia de quais métodos de programação seriam necessárias para que o robô fizesse o comando adequado, para que este realizasse uma ação semelhante como ao objeto real.

Com os protótipos robóticos prontos, os alunos foram construir a maquete de suporte para os brinquedos, foi o momento em que todos interagiram, pois todos estavam em prol de uma construção em comum. Com o Robôparque concluído, introduzimos a matemática financeira básica para problematizar a temática, onde buscamos levar os alunos a compreender o processo da construção de um negócio, levando em consideração investimentos, produto, lucros, despesas etc. Com isso alguns alunos mostraram sua desenvoltura em empreendedorismo, administração de empresas e até mesmo do seu próprio dinheiro.

\section{Conclusões}

Percebeu-se diante da proposta colocada que a Robótica Educacional permite ao aluno uma construção do seu próprio saber. A construção livre do protótipo utilizando o Kit LEGO $^{\circledR}$ Minsdstorms NXT 2.0 foi uma construção material de algo que os próprios alunos tinham uma referência, um modelo real. Essa proposta buscou contextualizar um mundo conhecido e relacionar no processo de construção e problematização do tema a construção do conhecimento matemático, raciocínio lógico e trabalho em equipe.

Para o grupo de bolsistas foi significante a construção dos alunos, mesmo diante das dificuldades encontradas. O grupo abriu lugar para novas propostas, sejam de construção livre ou com auxílio de montagem. A proposta instigou também dentro do projeto novas ideias para futuras atividades.

Entendemos com esta proposta que houve um envolvimento, sendo uma experiência marcante o que Barbosa (2016) no olhar de Jorge Larrosa, é algo marcante e que transforma os alunos, a forma de pensar e olhar o mundo. Todos os envolvidos, sejam alunos, bolsistas, orientadores, escola, passaram por uma experiência enriquecedora e motivadora para o desenvolvimento de novas ações que busquem explorar em temas, a criatividade e as possibilidades matemáticas, os modelos existentes naqueles contextos. 
VI Congresso Brasileiro de Informática na Educação (CBIE 2017)

Anais do XXIII Workshop de Informática na Escola (WIE 2017)

\section{Agradecimentos}

Agradeço a Universidade Federal de Goiás, a Fapeg, a Capes e principalmente a Escola CAIC São Francisco de Assis.

\section{Referências}

[1] ABReU, J.; BASTOS, B. Robótica Pedagógica e Currículo do Ensino Fundamental: Atuação em uma Escola Municipal do Projeto UCA. Revista Brasileira de Informática na Educação, Volume 23, Número 3, 2015.

[2] BARBOSA, F. C. Rede de aprendizagem em robótica : uma perspectiva educativa de trabalho com jovens. UFU, Uberlândia, MG, 2016.

[3] BARBOSA, F. C.; SOUZA JUNIOR, A. J. Robótica Educacional No Ensino Fundamental Público: Uma Arte De Fazer. Anais do XI Encontro Nacional de Educação Matemática, Curitiba - PR, 2013.

[4] FREIRE, P. Pedagogia da autonomia: Saberes necessários à prática educativa. São Paulo: Paz e Terra, 2003.

[5] JESUS, A. G. de. A motivação para aprender matemática no $9^{\circ}$ ano do ensino fundamental: um estudo do potencial dos materiais manipulativos e da construção de objetos na aprendizagem de área de polígonos e volume de prismas. 2011. 314p. Dissertação (Mestrado em Educação Matemática) - Universidade Federal de Ouro Preto, Ouro Preto, 2011.

[6] LOPES, C. C.; DUARTE, M. S. S. G.; SOUSA, E. A. D.; SOUZA, R. P.; PEREIRA, I. B. O Ensino de Algoritmos e Lógica de Programação como uma Ferramenta Pedagógica para Auxiliar a Aprendizagem de Matemática: Um Relato de Experiência. V Congresso Brasileiro de Informática na Educação CBIE, 2016.

[7] MAIESKI, S.; OLIVEIRA, K. L.; BZUNECK, J. A. Motivação para aprender: o autorrelato de professores brasileiros e chilenos. Psico-USF, Abr 2013, vol.18, no.1, p.53-64. ISSN 1413-8271

[8] MIRANDA, L. C.; SAMPAIO, F. F.; BORGES, J. A. S. RoboFácil: Especificação e Implementação de um Kit de Robótica para a Realidade Educacional Brasileira. Publicado na Revista Brasileira de Informática na Educação, Volume 18, Número 3, 2010.

[9] MORAES, M. C. Robótica Educacional: Socializando e Produzindo Conhecimentos Matemáticos. Universidade Federal do Rio Grande, Rio Grande, 2010 .

[10] PAPERT, S. A máquina das crianças: repensando a escola na era da informática. Porto Alegre: Artmed, 2008. 2014 p. (Ed. rev.). Tradução Sandra Costa. 
VI Congresso Brasileiro de Informática na Educação (CBIE 2017)

Anais do XXIII Workshop de Informática na Escola (WIE 2017)

[11] PAPERT, S. A Família em Rede: Ultrapassando a barreira digital entre gerações. Tradução de Fernando José Silva Nunes e Fernando Augusto Bensabat Lacerda e Melo. Lisboa: Relógio D’Água Editores, 1996.

[12] REY, F. G. Pesquisa Qualitativa e Subjetividade: os processos de construção da informação. Tradução de Marcel Aristides Ferrada Silva. São Paulo: Pioneira Thomson Learning, 2005.

[13] ZILLI, S. R. A Robótica educacional no ensino fundamental: perspectivas e prática. 89 f. 2004. Dissertação (Mestrado) - Curso de Programa de Pós-Graduação em Engenharia de Produção, Universidade Federal de Santa Catarina, Florianópolis. 